\title{
Acute diffuse leukoencephalitis in HIV-1 infection
}

\author{
Wilfried Lüer, Joachim Gerhards, Sigrid Poser, Thomas Weber, Klaus Felgenhauer
}

\begin{abstract}
The clinical, neuroradiological, and cerebrospinal fluid findings of a case with acute diffuse leukoencephalitis, a demyelinating disease associated with human immunodeficiency virus infection of the brain, is reported. The patient presented with acute tetraparesis as the primary manifestation of a previously symptom free HIV infection. Cerebrospinal fluid analysis showed enhanced inflammatory abnormalities with high concentrations of P24 antigen. MRI showed diffuse white matter hyperintensities in both hemispheres. In the follow up over 22 months, the neurological deficits disappeared after antiretroviral treatment in good correlation with improvements in MRI as well as in inflammatory cerebrospinal fluid abnormalities.
\end{abstract}

$(\mathcal{F}$ Neurol Neurosurg Psychiatry 1994;57:105-107)

The neurotropism of HIV-1 leads to a wide variety of neuropsychiatric syndromes. Acute viral meningitis at the time of seroconversion indicates early HIV invasion of the brain, but the most frequent finding is chronic encephalitis with deterioration of cognitive and motor functions in the final stages. Neuropathologically, HIV encephalitis is characterised by scattered microglial nodules, infiltration of macrophages, and multinucleated giant cells. HIV leukoencephalopathy represents another neuropathological entity with diffuse white matter pallor, myelin loss, and reactive gliosis. ${ }^{1}$ This manifestation appears in advanced stages of systemic disease and has been associated with secondary immunopathological or metabolic processes. ${ }^{2}$ Furthermore, multiple coexisting brain infections with herpes viruses or JC virus may superimpose on the HIV associated abnormalities. ${ }^{3}$ Acute leukoencephalopathy is not yet well established and two previously reported patients died within days. ${ }^{45} \mathrm{We}$ report the follow up of a case with acute diffuse leukoencephalitis, whose severe neurological symptoms reversed after antiretroviral treatment.

\section{Patient report}

The 35-year-old female intravenous drug abuser was found to be HIV antibody positive in 1985. The first CSF analysis was done in February 1986. Involvement of the CNS was suspected because the patient complained of headache. Oligoclonal bands and intrathecal HIV antibody synthesis indicated an HIV brain infection. The clinical staging was CDC stage II without any symptoms, and a brain CT scan was normal. In September 1989 she developed headache, vertigo, and progressive

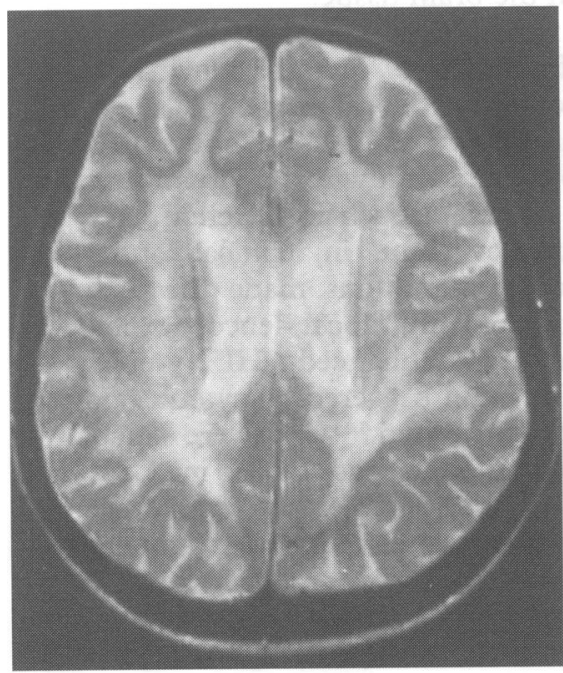

A

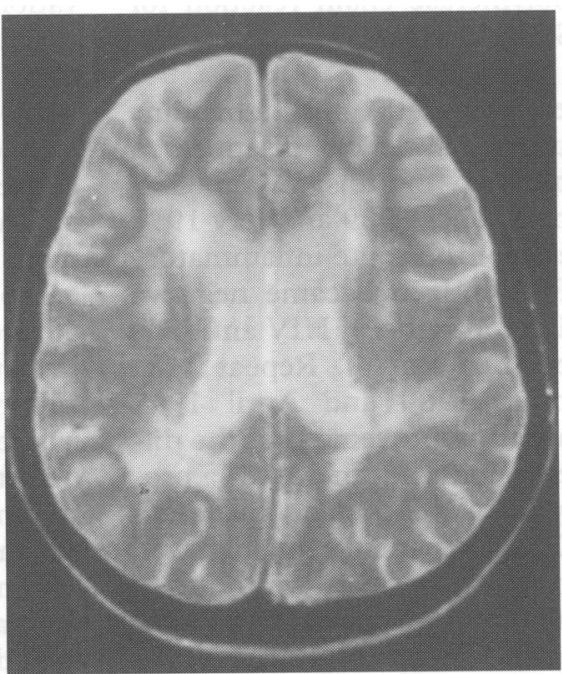

B

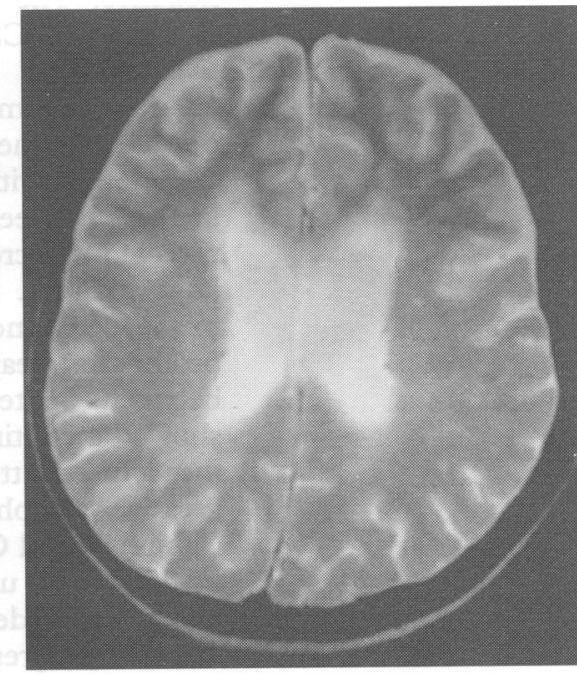

C

Figure 1 Reversal of the white matter hyperintensities in acute diffuse leukoencephalitis after antiretroviral treatment. (Magnetom, $1 \cdot 0$ or $1 \cdot 5 T$, T2-weighted images, $T R=2200-2500 \mathrm{~ms}, T E=90 \mathrm{~ms}$ ). (A) September 1989; (B) fune 1990; (C) April 1991. 
Table Cerebrospinal fluid abnormalities

\begin{tabular}{|c|c|c|c|c|c|}
\hline & \multicolumn{5}{|c|}{ Date of lumbar puncture } \\
\hline & February 1986 & September 1989 & October 1989 & December 1989 & fuly 1991 \\
\hline $\begin{array}{l}\text { Cells } / \mathrm{mm}^{3} \\
\text { Q }^{\star}{ }^{\star} \\
\text { Oligoclonal }\end{array}$ & $\begin{array}{l}1 \\
4 \cdot 9\end{array}$ & $\begin{array}{l}43 \\
28 \cdot 1\end{array}$ & $\begin{array}{l}26 \\
27 \cdot 7\end{array}$ & $\stackrel{9}{10 \cdot 8}$ & $\begin{array}{l}4 \\
5 \cdot 7\end{array}$ \\
\hline $\begin{array}{l}\text { bands } \\
\mathrm{IgG}_{\text {Loc }}(\%) \dagger \\
\mathrm{AI}_{(\mathrm{HIV})} \ddagger \\
\mathrm{AI}_{(\mathrm{CMV}} \ddagger \\
\text { P } 24 \mathrm{Ag} \text { (CSF) } \\
\text { P } 24 \mathrm{Ag} \text { (serum) }\end{array}$ & $\begin{array}{l}0^{+} \\
3 \cdot 7 \\
1 \cdot 0 \\
0 \\
0\end{array}$ & $\begin{array}{l}0 \\
12 \cdot 5 \\
0 \cdot 5 \\
2 \cdot 2 \\
+++ \\
+\end{array}$ & $\begin{array}{l}0 \\
22 \cdot 0 \\
4 \cdot 7 \\
\text { n.d. } \\
+++ \\
+++\end{array}$ & $\begin{array}{l}0 \\
50 \cdot 0 \\
4 \cdot 0 \\
1 \cdot 3 \\
+ \\
+\end{array}$ & $\begin{array}{l}+ \\
51 \cdot 0 \\
6 \cdot 4 \\
1 \cdot 0 \\
0 \\
(+)\end{array}$ \\
\hline
\end{tabular}

${ }^{\star}$ Blood CSF barrier function $=$ Albumin $_{(\mathrm{CSF})} /$ Albumin $_{(\text {Serum })} \times 10^{-3}$ (normal values $\left.<7.0 \times 10^{-3}\right)$; $\dagger$ Intrathecal immunoglobulin $\mathrm{G}$ production (\% of total CSF-IgG) $\ddagger \mathrm{AI}=$ Antibody index; $\mathrm{CMV}=$ cytomegalovirus; antibody indices above 1.5 indicate virus specific intrathecal antibody production ${ }^{8}$

lower limb weakness within two weeks and was admitted to the hospital. General examination was normal, immunological staging revealed $265 / \mathrm{mm}^{3} \mathrm{CD} 4$ cells. On neurological examination, the patient showed psychomotor slowing and severe tetraparesis and sensory loss, more prominent on the legs and the right side. Deep motor reflexes were reduced in the lower limbs with accentuation on the right side. Plantar responses were extensor on both sides. Bowel and bladder function were normal. An iridocyclitis and periphlebitis on both eyes suggested a cytomegalovirus infection.

The first MRI of the brain showed diffuse white matter lesions in the cerebral hemispheres and pons (figure (A)). Analysis of CSF showed a moderate lymphocytic pleocytosis with a severe impairment of the blood CSF-barrier (table). The intrathecal HIV antibody synthesis present in 1986 had disappeared, but higher P24 antigen concentrations in the CSF than in the corresponding serum sample indicated active virus replication within the brain (table). Examination of CSF for opportunistic brain infections with bacteria, herpes viruses, fungi, or protozoa were negative. Syphilis serology was negative in CSF and serum. At the onset of symptoms, there was a transitory intrathecal production of cytomegalovirus antibodies $\left(\mathrm{AI}_{\mathrm{CMV}}=2 \cdot 2\right.$, normal antibody index $\left.<1.5\right)$, but the polymerase chain reaction in CSF and serum for cytomegalovirus DNA was negative. The polymerase chain reaction for JC DNA in CSF and serum was also negative.

After treatment with $500 \mathrm{mg}$ zidovudine per day, the neurological deficits disappeared completely within two months. Serial CSF analysis between October 1989 and July 1991 revealed a decrease of the acute inflammatory abnormalities. P24 antigen became negative in the CSF, and the intrathecal HIV antibody production reappeared (table). Repeat MRI between September 1989 and April 1991 showed a continuous improvement of the diffuse white matter lesions, but there was a progressive atrophy with ventricular dilatation (figure (B and C)). The patient remained well in the follow up over two years without any neurological deficits and without significant disease progression since 1989; the CD4 counts were $367 / \mathrm{mm}^{3}$ in July 1990 and $176 / \mathrm{mm}^{3}$ in July 1991 .

\section{Discussion}

There have only been a few reports of acute and severe encephalitic syndromes in cerebral HIV-1 infection associated with the virus entry into the brain at the time of seroconversion. ${ }^{45}$ Furthermore, a fulminating or relapsing leukoencephalopathy indistinguishable from multiple sclerosis has been found in association with the $\mathrm{HIV}$ infection. ${ }^{67}$ In the present case, acute diffuse leukoencephalitis appeared four years after the systemic HIV infection was diagnosed. The development of neurological signs and symptoms are caused by an acute exacerbation of a previously symptom-free HIV-induced brain inflammation with corresponding MRI findings of bilateral diffuse white matter lesions. Also, severe CSF abnormalities including a strong intrathecal synthesis of P24 antigen were found at this time. The transient decrease of HIV antibodies in the CSF reflects antibody consumption in the CSF compartment, due to enhanced virus replication and formation of immune complexes. The demonstration of high P24 antigen concentrations in CSF is a reliable marker for active virus replication within the brain. The CSF P24 antigen did not originate from the circulating blood by passive transfer through the blood CSF barrier, because at onset of symptoms the P24 antigen concentration was higher in CSF than in serum. This supports the hypothesis that the systemic virus load seen four weeks later may originate from primary virus reactivation in the brain tissue.

The influence of concomitant viral infections (for example, cytomegalovirus or JC virus) on the development of the acute leukoencephalitis is still unknown. No evidence of coinfection with JC virus was found by the polymerase chain reaction, and the rapid improvement in clinical and radiographic manifestations made the diagnosis of progressive multifocal leucoencephalopathy unlikely. Enhanced HIV replication within the brain triggered by cytomegalovirus has been suggested. ${ }^{36} \mathrm{We}$ were unable to detect cytomegalovirus DNA in CSF and serum by the polymerase chain reaction, which argues against a direct influence of cytomegalovirus in this case. The retinitis was not associated with a concomitant brain infection, and the eye symptoms were self limiting without specific treatment. The transient intrathecal cytomegalovirus antibody 
production is interpreted as bystander reaction due to non-specific reactivation of cytomegalovirus specific memory cells in an enhanced inflammatory brain process. This phenomenon was often found in late stages of systemic HIV infection, where intrathecally produced herpes virus antibodies were found without evidence for active virus replication. ${ }^{8}$ Our data revealed substantial evidence that HIV is directly responsible for the acute leucoencephalitic illness, and possible coinfections with cytomegalovirus or JC virus that may cause white matter abnormalities could be excluded. Nevertheless, the exact aetiology of the acute white matter disease could only be provided by histopathological examination, which was not performed.

Several MRI studies showed diffuse abnormalities of white matter with slow progression of cognitive, behavioural, and motor abnormalities as the clinical manifestation of HIV induced dementia, ${ }^{9-11}$ but correlation with CSF analysis and longitudinal clinical findings are lacking. The patient reported here had acute neurological deficits due to diffuse white matter lesions. The severe neurological symptoms completely disappeared within two months after initiation of antiretroviral treatment in good correlation with improvements of the diffuse white matter hyperintensities as well as the severe CSF abnormalities. Although ventricular atrophy became prominent in the follow up, the radiographic findings did not correlate with any cognitive deficits or dementia.
The prevalence of acute diffuse leukoencephalitis remains comparatively small, but this manifestation expands the spectrum of direct HIV-associated brain diseases. Early antiretroviral treatment of symptom-free HIV infected persons may prevent this entity.

1 Budka H, Wiley CA, Kleihues $\mathrm{P}$, et al. Consensus report: HIV-associated disease of the nervous system: review of nomenclature and proposal for neuropathology-based terminology. Brain Pathol 1991;1:143-52.

2 Deicken RF, Hubesch B, Jensen PC, et al. Alterations in brain phosphate metabolic concentrations in patients with human immunodeficiency virus infection. Arch Neurol 1991;48:203-9

3 Budka H. Human immunodeficiency virus (HIV)-induced disease of the central nervous system: pathology and implications for pathogenesis. Acta Neuropathol (Berl) 1989;77:225-36.

4 Jones HR, Ho DD, Forgacs P, et al. Acute fulminating fatal leukoencephalopathy as the only manifestation of human immunodeficiency virus infection. Ann Neurol 1988;23:519-22.

5 Varma VA, Hunter S, Tickman R, Srinivasan A, Swan D. Acute fatal HIV encephalitis with negative serologic assays for antibody and antigen: Diagnosis by polyassays for antibody and antigen: Diagnosis by poly-

6 Gray F, Chimelli L, Mohr M, Clavelou P, Scaravilli F, Poirier J. Fulminating multiple sclerosis-like leukoencephalopathy revealing human immunodeficiency virus infection. Neurology 1991;41:105-9.

7 Berger JR, Tornatore C, Major EO, et al. Relapsing and remitting immunodeficiency virus-associated leukoencephalomyelopathy. Ann Neurol 1992;31:34-8.

8 Lüer W, Poser S, Weber T, Eichenlaub D, Jürgens S, Pohle HD, Felgenhauer K. Chronic HIV encephalitis. I: Cerebrospinal fluid diagnosis. Klin Wochenschr 1988; 66:21-5.

9 Kieburt KD, Ketonen L, Zettelmaier AE, Kido D, Caine ED, Simon JH. Magnetic resonance imaging findings in

10 Olsen WL Longo FM, Mills CM, Norman D. White matter disease in AIDS: Findings at MR imaging. Neuroradiology 1988;169:445-8.

11 Post MJ, Berger JR, Quencer RM. Asymptomatic and neurologically symptomatic HIV-seropositive individuals: Prospective evaluation with cranial MR imaging. Radiology 1991;178:131-9. 